\title{
Dominio Territorial
}

\author{
Por el Doctor RAUL FERRERO
}

El territorio de un Estado es la extensión comprendida dentro de sus fromteras, o sea el límite de su soberanía. Los modos de adquirir teritorios o, más propiamente, competencia sobre territorios, pueden ser agrupados en tres categorías, tal como distingue Rousseau: modos jurídicos, modo histórico-político y modos geogróticos.

A) MODOS JURIDICOS.- Han sido traspuestos de las instituciones de derecho privado, por analogía, salvo la adjudicación, que es forma tomada del derecho público interno. Los modos jurídicos se clasifican en originarios y derivados. Una adquisición se efectúa de modo originario cuando se trata de un territorio que no formaba parte de ningún Estado, caso actual de la accesión. La adquisición es derivada cuando tiene por objeto un territorio perteneciente $\alpha$ otro Estado.

Los modos jurídicos originarios son la acupación y la accesión.

La ocuparión de un territorio sin dueño o res nullius, se funda en el derecho natural y no puede ser ejercida sino por Estados, pues cuando la realiza un particular la soberanía corresponde al Estado respectivo. Jurídicamente, la ocupación es un acto de Estado, aun cuando la realizaren personas privadas. Los límites de la ocupación, o sea la extensión del territorio sometido, son determinados por la capacidad efectiva de imponer la autoridad del Estado ocupante.

Por extensión del derecho de ocupación, surgió la tesis del hinterland - tierra de atrás, zona de influencia (comprendiendo tierras situadas detrós de un litoral o en la cuenca de un río) que las potencias ofrecían respetar en el continente africano, por interés recíproco. Tuvo frecuente aplicación en la segunda mitad del siglo pasado. Las doctrinas de la continuidad $\mathrm{y}$ de la contigüidad son sistemas análogos que pretenden extender los efectos de la ocupación.

La accesión consiste en el aumento aportado a un territorio por un hecho tísico. Generalmente es natural, sea por aluvión o sedimentación gradual, por avulsión o arrancamiento, que consiste en la segregación súbita de una parte del territorio y su agregación al de otro Estado, por formación de islas, o por cambio de cauce de un río. También existe accesión artificial cuando, por efecto de obras de ingeniería, el territorio crece, como en los puertas o en una vasta región de Holanda, en la que el avance de territorio ha ocupado hasta el mar libre. 
Los modos derivajos son la cesión, la compra, el cambio y la prescrip zión.

Hay cesión en algunos tratados de paz, como sucedió con Alscicia y Lorena, en 1871, con Niza y Saboya en 1860 y con Tarapacá tras la guerra del Pacífico. Ello constituye una aberración jurídica, puesto que no se concilia con el derecho de conservación inherente a todo Estado. También hay cesión por plebiscito formal, que envuelve una presión o conquista no poicus veces. Hay venía de territorio cuando un Estado transfiere una región contra el pago de dinero, caso de la Louisiana vendida por Francia a los Estados Unidos en 1803, o de Alaska, vendida por Rusia en 1867, o de las Indias occidentales danesas, adquiridas por Estados Unidos en 1916. Los cambios de territorio, denominados canje o permuta, se efectúan generalmente para facilitar una delimitación racional de tronteras. Se adquiere por prescripción cuando media presión inmemorial, no interrumpida ni pertuibada, según estableció en el pasado la jurisprudencia internacional, como el caso del arbitraje del Rey de Italia respecto del diferendo entre Brasil y Gran Bretaña. Actualmente, la adquisición por usucapión o prescripción adquisitiva es controvertida fuertemente, además de que supone periocios de abondono seculares.

La adjudicación es el único modo de adquirir soberanía que se ha tomado o transpuesto del derecho público interno. Consiste en la atribución de un teristorio por vía de arbitraje, o por una Conferencia Internacional, o por un traiado multilateral, o por sentencia internacional. Debe distinguirse el caso en que consagra un derecho pre-existente, como el caso de la isla "Palmas", arbitraje de 1918, o sea cuando constituye un acio simpiemenie declarativo, del caso en que fija una frontera "ex equo et bono". coil la finalidad de asegurar la paz, porque entonces constituye un acto ctributivo que hacer nxcer el derecho, como sucedió en las Conferencias ce $\mathrm{Paz}$ de 1919 y después de la úlitima querra mundial.

B) MODO HISTORICO-POLITICO.-En el pasado, la aciquisición por conquista fue muy frecuente. La Revolución Francesa declaró solemnemente en 1790, que sus ejércitos no invocarian "el derecho de conquista" en los territorios que ccuparan; en sustitución, usó el plebiscito como forma de justificar la usurpación arguyéndose el reciente dogma de la soberanía nacional. Los países americanos han sido radicales en negar la conquista como título de dominio. Desde el Congreso de Panamá, 1826, y el de Lima, en 1865, han condenado, por inmoral, el llamado "derecho de conquista". El Presidente Wilson la proscribió solemnemente y el art. $10^{\circ}$ del Pacto de la Sociedad de las Naciones estableció: "los Estados miembros se comprometen a respetar y a mantener contra toda agresión exterior la integridad terriorial y la independencia política presente de todos los miembros de la Sociedad".

La doctrina Stimson, enunciada por los Estados Unidos en las notas cirigidas a los gobiernos de China y Japón, en 1932, con motivo de la campañc. de Mcnchuria, proclamó que no sería reconocida ninguna situación de hecho ni los tratados que se lograran por el uso de la fuerza. La Asamblea de la Sociedad de las Naciones consagró tal doctrina dos meses des- 
pués y la aplicó en numerosos casos, como en la guerra del Chaco y en la invasión de Etiopía. La VIII Conferencia Interamericana, reunida en 1938 emitió la Resolución de lima, declarando sin validez jurídica la ocupación - la adquisición de territorios, o cualquier arreglo de fronteras mediante la conquista por la fuerza o cualquier forma no pacífica. La Carta de las Naciones Unidas y la Carta de la Organización de Estados Americanos, 1948, han recogido tan importante principio.

C) MODOS GEOGRAFICOS.- Se fundan en la proximidad y ocultan propósitos anexionistas de fundamento muy debatido.

Según la doctrina de la continuidad, surgida como extensión implícita de la ocupación, por efecto de la posesión de una parte de determinado territorio debe considerarse ocupadas las tierras nullius, que forman unidad de hoya hidrográfica, o de relación geológica. Así lo adujeron los Estados Unidos frente a Gran Bretaña en el territorio de Oregón, sosteniendo que, por haber ocupado la desembocadura del río, tenían derecho a toda la cuenca hidrográfica. El tratado de 1848 no amparó dicha doctrina, pues reconoció a Gran Bretaña el dominio sobre la parte superior de la cuenca. Tampoco prosperó la pretensión de Gran Bretaña contra Venezuela tocante a la región de los ríos tributarios del Essequibo.

Para la doctrina de la contigüidad, o vecindad geográfica, los efectos de la ocupación se extienden a los territorios que se hallan separados por un brazo de mar, así como a las islas que están próximas al mar territorial del territorio ocupado. La doctrina ha sido aplicada en los archipitlagos del Pacífico, sosteniendo que la ocupación de una parte implica la del conjunto, en función de la adyacencia y de la dependencia geográfica.

\section{Régimen especial de las regiones polares}

Por tratarse de vastas zonas sin población, no ha podido aplizarso en ellas las reglas habituales para atribuir la soberanía. En la adquisición de las regiones polares, caracterizadas por la lejanía de las tierras, la pobreza biológica y el clima glacial, se han aplicado sistemas distintos, según se trate de la región áritica o de la antártica.

En el mar Artico, cubierto en gran parte por glaciares, se admite como título efectivo de soberanía el principio de vecindad geográfico, n sea de la contigüidad. Rige el sistema de triángulos esféricos, ideado en 1907 por el senador canadiense Poirier. Consiste en reconocer a cada uno de los países que tienen litoral sobre el Artico un sector triangular, cuya base es su línea de litoral. El polo norte sirve de ápice y los lados del triángulo están formados por los meridianos que pasan por los extremos del litoral respectivo.

Tal principio de los sectores ha sido aplicado con criterio geográfico e histórico. La U.R.S.S. ha delimitado su sector, que es el más vasto, por decreto de 1926. Los Estados Unidos, Canadá, Dinamarca y Noruega han trazado también sus regiones. Finlandia, que no tiene ribera sobre el Artico pero que llega a una distancia muy próxima, también invoca derechos. El extenso litoral de la U.R.S.S. abarca todo el norte del Ásia Y 
una parte de Europa, pero el sector más conocido e importante, del punto de vista de la utilización, está constituído por Groenlandia y su proyección, que son de soberanía danesa. Los vuelos regulares que se realizan a través del polo norte confieren a la zona ártica una creciente importancia próctica.

En la Antórtida prima una realidad muy distinta a la del mar Artico, pues se trata de un verdadero continente, cubierto todo el año por un espeso ccsquete de hielo. La aspereza de los vientos y el extremo rigor de la tem. peratura hacen imposible toda explotación y constituyen peligro grave para la vida humana. Ello ha determinado que ningún país pueda efectuar una ocupación contínua, salvo sobre áreas diminutas y sólo en la periferia. El principio de accesión o vecindad, que sirve de base a la teoría de los sectores, es de difícil aplicación a la Antórtida, pues ésta se halla a distancias enormes de los otros continentes, excepto Sudamérica. Además, su exiensión es tan considerable, quince millones de kilómetros cuadrados, que resultc desproporcionado proyectar sobre ella el derecho de adyacencia por parte de territorios notablemente menores.

Del punto de vista de la precisión geográfica, se admite generalmente una división de la Antártica en cuatro regiones o cuadrantes iguales, como referencia de ubicación y sin prejuzgar en cuanto al dominio. Mencicnados en el sentido de las agujas del reloj, los cuadrantes son los siguientes: el cuadrante sudamericano, que comprende de $0^{\circ}$ de Greenwich a $90^{\prime \prime}$ de longitud Oeste; el del Pacífico, de $90^{\circ}$ a $180^{\circ}$ de longitud Oeste; el australiano, de $180^{\circ}$ a $90^{\circ}$ de longitud Este, y el africano, de $90^{\circ}$ longitud Este c $0^{\circ}$. La denominación de cada cuadrante corresponde al continente $u$ océano al que hace trente.

Los Estados que mantienen pretensiones sobre la Antórtica invocan fundamentos muy diversos, de lo que resulta el intento de aplicar sistemas coexistentes. Los sectores se interfieren y superponen, como en el caso de los cie Chile y Argentina y de estos dos países con respecto a la pretensión británica.

El descubrimiento es invocado como título por la Unión de Repúblicas Soviéticas, Noruega, Francia y aún Australia, no obstante que la doctrina internacional niega validez al descubrimiento cuando éste no es seguido por una ocupación real.

La pretensión de Gran Bretaña se refiere al territorio de varios millones de kilómetros cuadrados, comprendidos entre los meridianos 20 a 55 de longitud Oeste y 50 a 80 de longitud Oeste, como masa antártica dependiente de las islas Malvinas. Además, Gran Bretaña pretende que el sectar denominado Tierra de Ross es dependencia de Nueva Zelandia.

Estados Unidos sostuvo tener derecho a la región denominada Tierra de Graham, sitc en el cuadrante sudamericano y descubierto por el marino norteamericano Palmer en 1820, pero desde 1924 ha venido declarando que no plantea ninguna pretensión dominial ni tampoco las acepta. En 1940, la expedición del Almirante Byrd realizó una invernada con gran éxito científico. La reciente actitud estadounidense consiste en auspiciar la internacionalización de la Antártica y su control o tutela ejercida por los 
países que tienen posesión o puntos de apoyo. Así lo propusieron por nota que enviaron en 1948 a los países interesados, de los que solamente Gran Bretaña no expresó rechazo.

Respecto de Chile y la Argentina existe una relativa vecindad, pues el extremo del continente dista de la Antártida 428 millas. Dado que la Cordillera de los Andes penetra en el mar en dirección a la tierra antár. tica, es fundado suponer que dicha formación orográfica se prolonga bajo el espeso casquete de hielo, por lo que ambos países invocan como título la continuidad geológica, así como la contiguildad o vecindad geográfica. Chile viene ejerciendo soberanía, de modo contínuo, mediante una base naval erigida en la bahía del Paraíso; por decreto del 6 de noviembre de 1940, ha fijado los límites de su territorio antártico entre los meridanos 53 y 90 de longitud Oeste de Greenwich. Ello abarca una parte considercble del cuadrante sudamericano; el meridiano 53 corresponde a la zona en que ha venido operando la Sociedad Ballenera de Magallanes desde principios del siglo y el meridiano 90 es el que pasa al Oeste de la isla Juan Fernández. Argentina, que mantiene un observatorio meteorológico en las islas Orcadas del Sur, ha fijado los límites de su territorio antártico entre los meridianos 25 y 74 de longitud Oeste de Greenwich. Por ccuerdo celebrado en 1950 convino con Chile y Gran Bretaña en no enviar duranie un año barcos de guerra al sur del paralelo 60, el cual sirve generalmente de base para los triángulos o sectores de pretensión dominial. Tal convenio, quo ha sido renovado anualmente, constituye sólo una tregua. Gran Bretaña colisiona sus pretensiones con los derechos argentinos, sobre todo por la proyección de las islas Malvinas. Argentina y Chile, por declaración conjunta efectuada en 1948, han convenido en actuar de común acuerdo en la protección y defensa jurídica de sus derechos antárticos, sin perjuicio de estudiar la delimitación de la región no definiáa entre ellos.

La idea del condominio, que propusiera Fauchile hace varias décadas, es de difícil aplicación pues entrañaría frecuentes disputas, aparte do que resulta superada por la de internacionalizar el continente antártico, so. metiéndolo al control de los ocho paises, como proponen los Estacios Unidcs.

Con ocasión del año geofísico internacional, en 1957, se definió unz tendencia hacia la cooperación internacional en las regiones polares, con fines científicos. En nuestra época, en que apunta ya una tendencix supranacienal, to razonable sería que la comunidad internacional aplicara su jurisdicción sobre los vastos territorios circumpolares de la región austral. por intermedio de un organismo especializado. Desde luego, ello comportaría la previa aceptación por parte de los países que ejercen soberanía de modo contínuo aunque ello sucede sobre extensiones muy reducidas.

Tocante al Perú, puede afirmarse que la expedición comandada por el navegante portugués Fernández de Quiroz, en uso de la autorizazión regia otorgada en 1605, le permite invocar título de descubrimiento. Dicha expedición partió del Callao y descubrió las islas Nuevas Hébridas, que recibieron el nombre de "Australia del Espíritu Sarito". En cuanto a los derechos que podríamos sostener sobre el cuadrante sudamericano, cabe determinar que la proyección de nuestro litoral comprende desde el meri- 
diano 77 hasta el meridiano 90 .

Las proclamas de Chile y Argentina en 1948, que determinaron la oposición de Gran Bretaña y la propuesta de someter el diferendo a la Corte Internacional, asi como la determinación de un sector ruso en 1949, han dado actualidad al debate sobre la Antártida. El tratado que se firmara en Washington en diciembre de 1959 prohibe el establecimiento do bases, la construcción de fortificaciones y la realización de maniobras de guerra, inclusive las explosiones nucleares. Dicho convenio ha cuidado de expresar que ninguno de los interesados renuncia a sus derechos de soberanía o reivindicación territorial.

MODALIDADES DE COMPETENCIA TERRITORIAL LIMITADA: SOn las siguientes: $\alpha$ ) condominios internacionales, como los de la isla de la Conferencia o de los Faisanes, en el río Bidasoa en la frontera hispono-francesa. - el que existe respecto de las aguas del Lago Titicaca, o de las aguas del Zarumilla; b) servidumbres internacionales, forma abolida al igual que ias Concesiones, subsisten en algunos casos, como sucede respecto del tráfico y de ciertos servicios portuarios en Arica; c) cesiones temporales, o sea arrendamiento o autorización para bases estratégicas, como la bahía de Guantánamo en Cuba o las bases que se han establecido por virtud de la OTAN: d) ocupación militar, sea en tiempo de guerra o por ejecución de un tratado de paz.

También pueden considerarse como modalidad de competencia territorial limitada la jurisdicción que ejerce el país costero sobre la "zona marítima contigua" y los llamados territorios bajo tutela (fideicomiso). La vigilancia aduanera, sanitaria y de defensa que se ejerce en la zona contigua constituye una competencia tragmentaria y especializada. Tocante a la conservación de los recursos marinos mediante zonas de preservación de amplitud mayor, ello configura una realidad nueva que desborda los conceptos tradicionales $y$ conduce a regímenes distintos a los antes vigentes, por una diferencia que es de naturaleza y no simplemente de grado. 